\title{
A disputa pelo sentido da "Mineiridade": A construção da imagem de Aécio Neves na disputa presidencial de 2014
}

\section{Paulo Roberto Figueira Leal}

Mestre e Doutor em Ciência Política pelo IUPERJ, professor e pesquisador do Programa de Pós-Graduação em Comunicação Social (PPGCOM) da UFJF. E-mail: pabeto_figueira@uol.com.br

\section{Luiz Ademir de Oliveira}

Mestre em Comunicação Social pela UFMG, mestre e doutor em Ciência Política pelo IUPERJ, é docente e pesquisador do Curso de Comunicação Social - Jornalismo da UFSJ e professor colaborador do Programa de PósGraduação em Comunicação Social (PPGCOM) da UFJF.

E-mail: luizoli@ufsj.edu.br
Resumo: $O$ artigo discute as construções identitárias do candidato Aécio Neves (PSDB) na disputa presidencial de 2014, tendo em vista que o tucano acionou símbolos que remetem à cultura da mineiridade. Ao mesmo tempo, o candidato priorizou, em vários momentos da propaganda, a campanha negativa de ataques à adversária Dilma Rousseff (PT), principalmente vinculando-a à era petista, à crise econômica e aos escândalos de corrupção na Petrobras. Pretende-se compreender como se dá esta mistura do velho e do novo numa política cada vez mais teatral e adaptada à lógica midiática, em que confluem os meios de comunicação massivos e os meios digitais. Serão analisados os programas do candidato no Horário Gratuito de Propaganda Eleitoral (HGPE) na televisão e as postagens em sua fanpage no Facebook.

Palavras-chave: Mídia e Política; Campanha Presidencial de 2014; Propaganda Política; Mineiridade.

The dispute over the sense of the "Mineiridade": The construction of the Aécio Neves image in the presidential race 2014

Abstract: The article discusses the candidate's identity constructions Aécio Neves (PSDB) in the presidential race in 2014 given that the toucan triggered intensely symbols that refer to the culture of mineiridade. At the same time, the priority candidate, at various times of propaganda, the negative campaign of the opposition attacks Dilma Rousseff (PT), particularly linking it to was PT, the economic crisis and the corruption scandals in Petrobras. The aim is to understand how is this mixture of old and new in an increasingly theatrical politics and adapted to the media logic, in which converge the means of mass communication and digital media. So both will be analyzed candidate programs in the Free Zone of Election Propaganda (HGPE) on television and in the posts on your fanpage on Facebook.

Keywords: Media and Politics; Presidential campaign of 2014; Political Advertising; Mineiridade. 


\section{Introdução}

A eleição presidencial de 2014, apesar de ter repetido no segundo turno a polarização entre PT versus PSDB, que já acontecia desde a disputa de 1994, foi um pleito com muitas peculiaridades. Até agosto, a dois meses da eleição, o cenário parecia não ter novidades. Dilma Rousseff (PT), candidata à reeleição, liderava com chances de vencer no primeiro turno contra Aécio Neves (PSDB). 0 candidato do PSB, Eduardo Campos, estava em terceiro, mas com poucas chances de romper o confronto entre petistas e tucanos. Mas a morte trágica de Campos num acidente aéreo no dia 13 de agosto gerou uma reviravolta na disputa, com a entrada em cena da ex-senadora Marina Silva, que era candidata a vice na chapa do PSB. As primeiras pesquisas após o início do Horário Gratuito de Propaganda Eleitoral (HGPE) apontavam que Marina não só poderia ir para o segundo turno contra Dilma, mas tinha se tornado favorita. Foi neste contexto de imprevisibilidade que pesou as estratégias de marketing eleitoral da candidata Dilma que investiu na desconstrução da imagem da candidata adversária. A petista, em sua propaganda, passou a mostrar possíveis ambiguidades no posicionamento político e ideológico da candidata socialista e, aos poucos, os números mostraram uma retomada da liderança por parte de Dilma. O resultado do primeiro turno surpreendeu com a ascensão de Aécio Neves, que ficou em segundo lugar, mas com apenas $8 \%$ atrás da petista. $O$ tucano entrou no segundo turno em vantagem e chegou a liderar as primeiras pesquisas. Com altos investimentos em marketing eleitoral e com uma das campanhas mais acirradas, os candidatos abusaram da propaganda negativa. Tanto na propaganda política e eleitoral quanto nos debates e nas entrevistas para a imprensa, Dilma e Aécio trocaram acusações. O resultado deu uma vitória apertada a Dilma com pouco mais de 3 milhões de votos à frente do tucano $-51,64 \%$ contra $48,36 \%$.

A partir desta apresentação do cenário eleitoral da eleição de 2014, o artigo tem como proposta discutir as implicações das tensões do campo da política na esfera midiática, focando na análise das estratégias de campanha do candidato Aécio Neves. O intuito é mostrar as mudanças que se efetivaram nos modelos de propaganda política no Brasil, com a crescente importância do uso da internet e das redes sociais. A disputa, antes centrada no rádio e na televisão no Horário Gratuito de Propaganda Eleitoral, ganhou importância também no ciberespaço, a partir da ideia de uma narrativa transmidiática. Nos sites, nas redes sociais, discursos e, principalmente, estratégias de propaganda negativa ganharam força para desconstruir os adversários.

No caso do candidato Aécio Neves, o trabalho parte da concepção de identidades híbridas (HALL, 2004) para compreender como o tucano oscilou de um discurso que enfatizou a postura conciliadora do político mineiro até um posicionamento mais ofensivo de ataques à candidata do PT, rompendo com os princípios da chamada cultura da mineiridade. Para isso, além do arcabouço teórico e conceitual, o artigo recorre a evidências empíricas tanto dos programas do Horário Gratuito de Propaganda Eleitoral como da fanpage do candidato. Dados da Secretaria de Comunicação do governo federal (SECOM) sobre hábitos de consumo de mídia no Brasil (Pesquisa Brasileira de Mídia - PBM) revelam que, em 2015, a televisão mantém-se como meio de maior penetração (95\%), seguido do rádio (55\%). Mas a internet já é a mídia preferida por $48 \%$ dos entrevistados e estes números são bem mais expressivos se levar em conta os mais jovens, com maior escolaridade e maior renda. Isso revela que o panorama de consumo de mídia no país vem se modificando, o que exige novas estratégias dos atores políticos e dos profissionais de comunicação e de marketing. 


\section{A identidade: as contribuiç̧̃es do interacionismo simbólico e dos Estudos Culturais}

Quando falamos de identidade, cabe ressaltar, recorrendo a Erving Goffman (1999), que as interações sociais, sejam ela face a face ou mediadas pelos meios de comunicação, estabelecem-se a partir de um jogo de representações de papéis. Logo, encontramos diferentes formas de representação que variam de acordo com o contexto social, cultural, político, econômico, nos quais os indivíduos se encontram, variando também em função das diferenças de perfil psicológico de cada um.

Nesse processo, de acordo com Goffman (1999), o indivíduo pode situar-se em dois extremos. O primeiro é aquele no qual o homem está convencido de seu ato, ou seja, está sinceramente convicto de que a vivência de realidade que encena é a verdadeira realidade. $O$ outro extremo apresenta-se quando o indivíduo é cínico a respeito dele próprio, ou seja, ele não crê em sua própria atuação e não se interessa pelo o que os demais pensam dele. Assim, se o indivíduo representa papéis, é necessário levar em consideração a oscilação natural entre cinismo e sinceridade.

Goffman explica que não é por acaso que a palavra "pessoas", em sua acepção primeira, queira dizer máscara, mas se trata do reconhecimento do fato de que todo homem está sempre e em todo lugar, mais ou menos conscientemente, representando um papel. É nesses papéis que nos conhecemos uns aos outros; é nesses papéis que nos conhecemos a nós mesmos (PARK in GOFFMAN, 1999: 27).

Para o indivíduo representar, é necessário um equipamento expressivo de tipo padronizado intencional ou inconscientemente empregado por este, denominado de fachada pelo autor, "que é parte do desempenho do indivíduo que funciona regularmente de forma geral e fixa com o fim de definir a situação para os que observam a representação" (GOFFMANN, 1999: 29). O cenário pode ser compreendido como a mobília, a decoração, a disposição física, entre outros elementos de pano de fundo que assim constituem o ambiente e os suportes de palco para o indivíduo executar a sua ação humana, a representação. Uma vez que a sua tendência é estar limitado a uma dada posição geográfica, somente em circunstâncias excepcionais o cenário acompanha os atores. Goffman (1999) também analisa a "fachada pessoal", constituído pelo vestuário, características raciais, aparência, expressões faciais, gestos corporais, altura, entre outros. Alguns deles são relativamente fixos, como as características raciais do indivíduo e outras relativamente móveis que podem variar, como a expressão facial, por exemplo. $\mathrm{O}$ uso da dramatização no ato de representar se torna necessário para que a atividade do indivíduo se torne significativa para o outro, uma vez que essa expressão de qualidades, que acentuam e configuram sinais, são essenciais para criar uma visibilidade favorável ao ser em questão. Mas o autor pontua "o problema de dramatizar o próprio trabalho implica em mais do que simplesmente tornar visíveis os custos invisíveis" (GOFFMAN, 1999: 38).

A representação é um ato socializado, pois esta é adaptada para assim atender à expectativa da sociedade em que é apresentada. Os atores tendem a oferecer a seus observadores uma impressão que é idealizada de várias e diferentes maneiras, para assim agradarem a seu público. Assim, quando o indivíduo se apresenta diante dos outros, seu desempenho tenderá a incorporar e exemplificar os valores oficialmente reconhecidos pela sociedade e até realmente mais do que o comportamento do indivíduo como um todo (GOFFMAN, 1999: 41). 
Em decorrência das profundas metamorfoses ocorridas no decorrer do século XX e XXI - a intensificação do processo de globalização e a emergência das tecnologias digitais, por exemplo - a vida social e as manifestações culturais passaram por mudanças que interferiram diretamente no cotidiano dos indivíduos. Constata-se, nos dias atuais, um sujeito perdido face a tantas transformações e a uma certa perda de referências. Alguns autores acreditam que o conceito de identidade pode ser alterado por identificações, já que o indivíduo oscila cada vez mais de papéis sociais e está em permanentes mutações no que diz respeito a valores, condutas, nos mais diferentes campos sociais político, religioso e até mesmo em relação à sexualidade. Stuart Hall (2004) explica estas transformações que vêm ocorrendo no campo da identidade que se efetivam, principalmente, a partir do final do século XX. O autor argumenta que houve uma fragmentação da vida social e as concepções que se tinha de classe social, gênero, sexualidade, etnia, raça e nacionalidade perderam o seu significado ou se tornaram relativos. O quadro de referência se esvaziou e deixou o indivíduo numa permanente busca de identificações. Hall afirma que essa perda do eu pode ser conceituada como deslocamento ou descentramento do sujeito.

A partir de tais constatações, Hall argumenta que se deve trabalhar com a ideia de que há a emergência de um novo sujeito, o sujeito pós-moderno, que não está atrelado a identidades fixas, mas que está em permanente mutação de papéis sociais diante a uma dinâmica acelerada da vida social. Nesse contexto, a própria identidade tende a ser compreendida a partir da noção de mobilidade. Tem-se um sujeito que encarna uma diversidade de papéis socais ou identidades, muitas vezes contraditórias entre si, chamado pelo autor de sujeito pós-moderno.

Nesta linha de estudos, Castells (1999) discute a identidade como uma multiplicidade de papéis representados no cotidiano de cada indivíduo. Suas experiências, seus hábitos e seu meio, estruturado e definido pelas instituições e organizações da sociedade. Aos papéis cabe a representação do ator, a organização das funções que cada indivíduo exerce enquanto pessoa que vive e participa de uma sociedade, enquanto a identidade organiza o significado, que Castells define como identificação simbólica por parte de um ator social.

Castells propõe três formas de origem da construção de identidades: identidade legitimadora, identidade de resistência e identidade de projeto. $O$ autor explica que as relações de poder são as responsáveis pela construção social da identidade. As manifestações identitárias são caracterizadas pela história de cada grupo. Algumas desenvolvem uma prática renovadora, enquanto outras se caracterizam pela resistência à mudança, outros por projetos de futuro. Obviamente, identidades que começam como resistência podem acabar resultando em projetos, ou mesmo tornarem-se dominantes nas instituições da sociedade, transformando-se assim em identidades legitimadoras para racionalizar sua dominação. $\mathrm{Na}$ atualidade, o processo de construção da identidade vem passando por várias transformações, frente à globalização e avanços tecnológicos.

\section{A cultura da mineiridade}

Conforme explica Ângelo (2005), a mineiridade está, muitas vezes, associada a elementos como a pacatez, a vida rural e a morosidade, mas afirma que o termo mineiridade adquire maior amplitude e complexidade quando investigado em sua dimensão ideológica. A identidade mineira, conforme explica Lima (2000), citado por Ângelo (2005), engloba três aspectos principais: (a) a valorização mítica do passado de riquezas, exploração e luta pela liberdade em Minas, o que gera uma forte tendência memorialista e tradicionalista; (b) a habilidade do político mineiro visto como um líder conciliador em função de seu equilíbrio, bom senso e 
valorização da estabilidade; (c) a participação estratégica na construção de um Estado que tenha uma perspectiva de unificação nacional, já que o Estado é visto como o centro político e geográfico do país, aliado a um apego a terra, à paisagem e aos valores locais.

Arruda (1990) explica a concepção de mineiridade a partir de dois aspectos: a trajetória histórica do Estado de Minas Gerais e a noção de mito, extraída do campo da Antropologia que parte da ideia de que a capacidade de apreensão do tempo cronológico em Minas como sendo cíclico, acentuando o caráter mítico do mineirismo. A exploração do ouro e a política de exploração por parte de Portugal através da cobrança de impostos elevados gerou descontentamentos que culminou na Inconfidência Mineira. Segundo Arruda (1990), a identidade mineira começou a ser gerada a partir da experiência de uma derrota, ligada, principalmente, ao ideário da Inconfidência. Segundo Ângelo (2005), a Conjuração Mineira despertou a noção de que os mineiros reagem às formas de despotismo em nome da liberdade, tendo sido personificado na figura do mártir Tiradentes, que oscilava entre as elites e a classe popular. A rebeldia regional tornou-se símbolo de uma defesa da nação. 0 dia 21 de abril tornou-se um momento marcante para a identidade nacional. A postura patriótica de Tiradentes, segundo Arruda (1990), remete, de forma implícita, a uma narrativa mítica sobre a Paixão de Cristo - o sofrimento, o Calvário.

Arruda (1990) argumenta que outra figura que retomou esta imagem mítica foi Tancredo Neves. A morte de Tancredo gerou comoção nacional. Segundo a autora, os fatos ocorridos durante a doença de Tancredo Neves quando foi eleito presidente da República - e era a grande esperança do povo brasileiro - trazem semelhanças com os passos do calvário e com a luta de Tiradentes. Coincidentemente, para reforçar o valor mítico, a morte de Tancredo ocorreu no mesmo dia da morte de Tiradentes, o que trouxe uma forte carga simbólica para o imaginário do povo brasileiro.

Ângelo (2005) pontua que a Inconfidência deve ser entendida num contexto mais amplo em que Minas Gerais passava por um período de transição. Aos poucos, com a queda da exploração de ouro, o Estado perdeu importância econômica e cresceram as taxas de emigração. Na década de 20 do século XX, Minas perdeu o posto de estado mais populoso para São Paulo. Arruda (1990) afirma que a mudança da atividade mineradora para atividades agrícolas traz um significado mais amplo: a mineração envolve fatores como a aventura (perigo e descobertas), mobilidade (busca de novas lavras) e insegurança (física e financeira), enquanto as atividades agrícolas remetem ao contrário estabilidade, segurança e tranquilidade. Segundo a autora, isso faz com que as elites mineiras repensem as suas estratégias de atuação no campo da política nacional - de contestadores e rebeldes passam a ser os conciliadores, os que buscam a integração e a ordem, que está hoje muito presente na ideia de mineiridade.

De acordo com Ângelo (2005), a ênfase na habilidade política, na capacidade de articulação, na moderação e no equilíbrio já eram características presentes na idéia de mineiridade mesmo antes do declínio econômico. Lima (2000), citado por Ângelo, sugere ao leitor que tais características estão relacionadas à própria geografia de Minas - a importância da Montanha como marca do território mineiro. O montanhês representa, segundo o autor, horizonte limitado, ritmo lento, concentração e equilíbrio. Ângelo (2005) aponta ainda outras características decorrentes do fato de Minas ser um estado montanhês: (a) dominação da vontade, do pragmatismo sobre a imaginação, como a busca de acordos, a negociação, a tentativa de conciliação; (b) a posição central em relação aos outros estados faz com que Minas sofra influências das mais diversas regiões 
tanto internas como de outras federações; (c) por ocupar um espaço central, acaba assumindo o papel de unificação inter-regional, que se reflete no caráter unificador, apaziguador, conciliador dos mineiros. Segundo o autor, a presença dos mineiros em inúmeros momentos cruciais da história política nacional garante-lhes espaço privilegiado no cenário público brasileiro.

Conforme explica Ângelo, para manter a sua força ideológica, a mineiridade constitui-se em estrutura mítica, recorrendo sempre ao passado, às origens, para se reforçar. Por isso, concebe o tempo como cíclico e não linear. No imaginário da mineiridade, segundo o autor, destacam-se a luta pela liberdade, a valorização da família, a preservação dos regionalismos, a saudade do vilarejo, o caráter montanhês, entre outros aspectos. No caso da política, o recurso ao passado é uma forma de garantir um espaço estratégico.

\section{Nova "ambiência eleitoral": o caráter personalista e a narrativa transmidiática}

Para entender o conceito de poder, a obra "Microfísica do poder", de Michel Foucault (2003) é uma das grandes referências. O autor desmistifica o argumento de que o poder é algo centralizado, unilateral, mas, ao contrário, trabalha com a ideia de que o poder está disseminado de forma heterogênea nas várias instâncias sociais. Na perspectiva de Foucault, as relações de poder não são naturais, mas são instituídas a partir de um contexto histórico e social. Ele afirma ainda que o poder funciona em rede e não deve ser entendido apenas como sinônimo de práticas coercitivas e que remetem à proibição. Para Foucault, o poder instaura a partir de estratégias de sedução que camuflam o seu caráter repressor. Daí decorre a atualidade do pensamento do autor para se compreender as relações de poder instituídas numa era marcada por novas configurações sociais pautadas, principalmente, pela centralidade do campo da mídia.

Isso remete à concepção de poder simbólico formulada por Bourdieu (1998), compreendido a partir da delimitação dos diferentes campos sociais. Ao tratar da representação política, o autor argumenta que as formas de percepção e expressão política se limitam a grupos destinados a produzir ideias, conceitos, análises e problemas políticos. Esses grupos limitados tendem a oferecer aos "consumidores" os discursos que representam os atos políticos. Tal fenômeno, chamado por Bourdieu de "mercado da política", é composto por profissionais e atores envolvidos nesse processo. A mídia pode ser compreendida ainda como um mecanismo de aproximação de agentes distantes do chamado "jogo político". Nesse sentido, o campo da política precisa recorrer ao campo midiático para aproximar o eleitorado.

Isso porque a mídia tem uma função de centralidade na sociedade contemporânea, ao se constituir como um referencial de mundo. Rodrigues (1990) explica que, se, nas sociedades antigas, os mitos eram a referência de mundo, na era moderna, o discurso da mídia surge para dar uma ordem ao universo. Ou seja, a partir de fragmentos aleatórios do real, o discurso da mídia cria uma suposta ordem política, econômica e cultural que dá ao público a sensação de estar num mundo repleto de sentido. Além disso, hoje, cabe ao campo midiático o papel de servir de mediador da vida social (Rodrigues, 1990). É no campo dos media que os outros campos sociais buscam, estrategicamente, dar visibilidade e legitimar suas ações.

Alguns autores discutem o que seria esta mudança de representação política. Manin (1995) afirma que o governo representativo passou por três fases: (a) democracia parlamentar - refere-se às democracias incipientes do século XVIII, nas quais a relação entre representantes e representados era praticamente face 
a face; (b) democracia de partido - no século XIX, quando as cidades se tornam metrópoles e o contato passa a ser mediado pelos partidos políticos de massa. Vota-se no partido e não nos representantes; (c) democracia de público - nos anos 1980, Manin identifica uma mudança de representação, com o declínio dos partidos políticos e o foco cada vez maior nos líderes personalistas, no caráter plebiscitário das eleições e no papel estratégico da mídia nas campanhas eleitorais.

Como foi mencionado anteriormente, vivenciamos um momento de transição em termos de consumo de mídia. A televisão ainda tem uma grande penetração e importância, o que traz impactos para as disputas eleitorais. Albuquerque (1999) analisa como existe um modelo brasileiro de propaganda política, focado, principalmente, nos programas do Horário Gratuito de Propaganda Eleitoral. Para isso, o autor define três tipos de segmentos de campanha: os segmentos de campanha que se referem aos conteúdos políticos (imagem do candidato, ataque aos adversários, temas políticos, construção da imagem do país), os segmentos de metacampanha que tratam do andamento da campanha (cenas de campanha, divulgação de pesquisas de opinião, depoimentos de apoios, pedagogia do voto etc.) e os segmentos auxiliares que dão a identidade da campanha, como vinhetas e jingles. Até 2010 , as campanhas para cargos majoritários eram centradas basicamente nos programas do HGPE. No entanto, as eleições de 2012 e 2014 passaram a contar com a inserção cada vez maior da internet. Mesmo que como um espaço ainda complementar, o ciberespaço fez com que o modelo de propaganda convencional na mídia massiva tivesse que ser repensado. Hoje, as estratégias de campanha precisam pensar nos diversos suportes midiáticos e prevalece a narrativa transmidiática.

Nesse sentido, quanto ao ciberespaço, constata-se uma efervescência de conceitos a partir do surgimento da internet como principal produto da revolução tecnológica, e a cibercultura passa a desempenhar papel crucial na sociedade. Jenkins (2009) discute os conceitos de convergência e narrativa transmidiática. $O$ autor explica que a convergência refere-se ao fluxo de conteúdo acionado por meio de variadas plataformas de mídia, além do comportamento migratório dos públicos dos meios massivos para os meios digitais. Jenkins explica que convergência implica um processo de transformações tecnológicas, mercadológicas, culturais e sociais, até porque exige uma nova postura do público que passa a ser estimulado a procurar novas informações e estabelecer novas conexões em meio a uma gama ampla de mídia que estão dispersos no ciberspaço.

Raquel Recuero (2009), ao discutir o advento da comunicação mediada por computador (CMC), argumenta que, mais do que permitir ao indivíduo comunicar-se, ampliou a capacidade de conexão e permitiu que redes fossem criadas. $O$ estudo das redes sociais, segundo a autora, deve ser feito a partir de uma perspectiva sistêmica, de que não são independentes de outros processos. Articulam-se as dimensões tecnológicas às mudanças sociais e nas interações. $A$ autora afirma que a rede social é definida como um conjunto de dois elementos: os atores (pessoas, instituições ou grupos - os nós da rede) e suas conexões (ou laços sociais) que são estabelecidas. Quanto aos atores, nas redes sociais os indivíduos ou grupos atuam para desenvolver técnicas de aparição e de controle da sua visibilidade, como ocorre nas fanpages. Quanto às conexões, segundo Recuero, permitem que se compreenda a estrutura social, quais são os atores estão vinculados, que tipos de interações sociais são estabelecidas e por que as interações tendem a permanecer no ciberespaço, permitindo a percepção das trocas sociais. 
Por isso, é possível estudar a interação social no ciberespaço até como forma de entender os vínculos que os indivíduos e grupos estão criando. No caso das fanpages dos candidatos, percebe-se que se trata de grupos políticos em conflito e, conforme denomina Recuero, de redes sociais associativas, já que tendem a agregar indivíduos que se associam a determinada linha política. Por fim, a autora discute o conceito de capital social, compreendido como um conjunto de recursos de um determinado grupo acumula e que pode ser usufruído por todos os membros desse grupo. Portanto, é uma forma de construção de capital social. Se a democracia digital possibilita novas formas de interação e de participação política, destacam-se os investimentos cada vez maiores em ferramentas como as redes sociais, como é o caso do facebook nas disputas eleitorais.

Camilo Aggio (2013) centra sua discussão no uso das plataformas da internet nas campanhas eleitorais como uma estratégia relativamente recente nas democracias contemporâneas, que teve início na década de 90 em campanhas nos Estados Unidos. Mas somente no século XXI com o potencial da web 2.0 que as estratégias de campanhas passaram a explorar questões que são próprias da internet, como a interação, a participação em tempo real, a convergência de mídia. $O$ autor destaca quatro pontos-chaves na sua análise da internet e o seu uso em estratégias de campanhas eleitorais: (a) o fornecimento e informações não mediadas pelos media noticiosos; (b) paridade de disputas entre campanhas de pequeno e grande porte; (c) interatividade; (d) ativismo. No que diz respeito às diferenças entre a campanha na web e nos meios massivos (TV e rádio), Camilo Aggio (2013) traça alguns pontos importantes.

\begin{abstract}
A grande diferença entre a televisão, o rádio e a Internet, então, estaria na forma de interação e de participação que a última oferece. Ao passo que os dois primeiros têm objetivos específicos claros de construir imagens e passar com eficiência uma mensagem e prescindir de contatos diretos, interativos, a terceira proporciona uma maior aproximação da campanha ao possibilitar a troca de mensagens, produzindo um efeito de sentimento de pertença e configurando elementos de participação. Se, por um lado, os novos mecanismos de participação servem às estratégias de fidelização prescritos pelo marketing político, por outro lado há práticas que podem assegurar que a interferências e sugestões dos cidadãos de fato sejam levadas em consideração. Invariavelmente, nesta circunstância, não há possibilidade de dissociar o que seria da ordem do marketing político e o que seria da ordem de uma diferenciação do modo de fazer campanha com reflexos do incremento à democracia (AGGIO, 2013: 180).
\end{abstract}

Dando prosseguimento a sua argumentação, Aggio cita alguns canais de participação do eleitor nas campanhas pela web, como e-mails, salas de batepapo, sondagens de opinião. Percebe-se que o autor está mais centrado no papel dos websites e em seus recursos interativos. Mas, nas campanhas as redes sociais, como Twitter, Facebook e Instagram, têm uma penetração muito maior e há, inclusive, maior investimento por parte dos candidatos.

Apesar do potencial interativo e de se poder incrementar a participação, o que seria um grande avanço para as democracias, Aggio explica os motivos da baixa interatividade com base em estudos, principalmente nas campanhas em países como os Estados Unidos e países europeus. Uma das dificuldades é de que a comunicação iniciada entre eleitores ou entre candidatos e eleitores se perca no processo, tendo em vista a velocidade dos fluxos informativos na web. Outros três problemas apontados por Galley (2000) e Kamark (2002), citados por Aggio (2013), dizem respeito: (1) problemas de escala e de complexidade das questões e circunstâncias referentes ao ambiente eleitoral; (2) o fato de os líderes de partidos e membros partidários terem o poder de tomar decisões ágeis e precisas para garantir a eficiências das campanhas, o que interfere num processo mais 
dialógico com os eleitores; (3) os líderes políticos e os responsáveis pelo marketing das campanhas precisam, às vezes, fazer mudanças estratégicas rápidas durante as campanhas eleitorais.

No caso do Brasil e mais especificamente na disputa presidencial de 2014, identificam-se outros agravantes que impossibilitaram um uso mais interativo da internet e das redes sociais. Podem ser citados: (a) o caráter peculiar da disputa eleitoral com uma série de imprevistos e reviravoltas em função da morte trágica do candidato Eduardo Campos; (b) o investimento tardio dos candidatos nas ferramentas da web; (c) o poder ainda muito concentrado nas mídias massivas tradicionais, como a televisão e o rádio; (d) a influência da grande imprensa em pautar e interferir nos processos políticos e eleitorais no país; (e) a falta de uma cultura política participativa no Brasil não somente nas disputas eleitorais, mas ao longo dos mandatos.

\section{Análise da construção da imagem do candidato Aécio Neves: a identidade a partir da ótica da mineiridade}

Para desenvolver a análise de conteúdo, foi feita uma pesquisa documental tanto dos programas exibidos na televisão no Horário Gratuito de Propaganda Eleitoral (HGPE) quanto na fanpage do candidato Aécio Neves (PSDB). Foram definidas como categorias de análise: (a) a construção da imagem sob o prisma da cultura da mineiridade; (b) a identidade híbrida - entre o tom conciliador e a postura crítica e agressiva.

Quanto à trajetória de Aécio Neves, iniciou sua carreira política em 1981, trabalhando com o seu avô Tancredo Neves no governo de Minas Gerais. Entre os anos de 1986 e 2002, cumpriu quatro mandatos seguidos de deputado federal ainda pelo PMDB. Em 1989, filiou-se ao PSDB e em 1997 passou a ser um político influente nas decisões do partido na Câmara, tornando-se líder do PSDB no Legislativo. Em 2001, foi eleito presidente da Câmara dos Deputados, e, em 2002, foi eleito o político mais influente do Congresso. Em 2002, ainda, iniciou um novo ciclo na sua vida política ao se candidatar ao governo de Minas, tendo sido eleito ainda no primeiro turno com $60 \%$ dos votos válidos. Em 2004, implantou o chamado "Choque de Gestão", que foi usado como um dos grandes feitos por seu governo ao gerar um déficit nas contas públicas do Estado, mas por ser criticado pela oposição de não passar de uma estratégia de marketing. Foi reeleito em 2006 com 73\% dos votos válidos. Em 2008, na disputa pela Prefeitura de Belo Horizonte, fechou um acordo com segmentos do PT, liderados pelo ex-prefeito da capital mineira, Fernando Pimentel (PT), para articular a candidatura de Márcio Lacerda (PSB), com a polêmica de que era possível unificar as forças divergentes no país em torno de um projeto nacional. Lacerda foi eleito com o apoio de tucanos e petistas. No entanto, depois o PT acabou rompendo com o prefeito do PSDB. Em 2010, depois de não conseguir ser o candidato do PSDB à Presidência da República, elegeu-se senador por Minas e ainda fez o seu sucessor no governo mineiro, com a vitória de Antônio Anastasia (PSDB). Em maio de 2013, já pensando em se tornar o candidato do PSDB à Presidência, foi eleito por ampla maioria dos delegados do partido Presidente Nacional do PSDB.

Em relação à conjuntura política, o quadro político mostrou-se instável desde a onda de protestos em junho de 2013 e tornou-se mais imprevisível com a morte do ex-governador Eduardo Campos (PSB). Tomando como base pesquisas divulgadas pelo Instituto Ibope, fica evidente como a disputa tornou-se imprevisível com a entrada de Maria Silva no lugar de Eduardo Campos. Marina tornou-se favorita, mas na reta final do primeiro turno perdeu espaço e Aécio alcançou $31,54 \%$ dos votos válidos, contra $21 \%$ de Marina Silva e garantiu uma vaga no segundo turno, ficando apenas 8 pontos percentuais atrás da candidata 
Dilma (41,59\%). O segundo turno trouxe a disputa mais acirrada da história política recente do país entre Dilma e Aécio. O tucano começou com uma virada conforme indicavam as pesquisas de opinião pública logo após o resultado do primeiro turno, mas a petista reverteu a situação e venceu com uma margem pequena de votos - Dilma teve 54.501 .118 votos ( $51,64 \%$ dos votos válidos) contra 51.041.155 votos de Aécio (48,36\%).

Quanto ao tempo no HGPE, Dilma saiu beneficiada pelo amplo leque de partidos aliados. Dilma, no primeiro turno, contou com mais de 11 minutos de propaganda política no Horário Gratuito de Propaganda Eleitoral (HGPE), por ter um amplo leque de partidos aliados (além do PT, PMDB, PR, PDT, PSD, PP, PC do B, PRB, PROS). Isso representou mais do que o dobro do tempo de Aécio Neves, que teve o apoio de poucos partidos - PSDB, DEM e SDD e algumas siglas consideradas nanicas, o que deu ao candidato 4 minutos e 35 segundos. Maria Silva, do PSB, teve, o apoio do PPS e de mais 4 partidos nanicos, com um tempo de pouco mais de 2 minutos. No segundo turno, o tempo no HGPE passou a ser igual para Dilma e Aécio, de 10 minutos para cada no programa da tarde e 10 minutos no programa da noite. Mas os candidatos investiram nas campanhas na internet, com websites e, principalmente, nas redes sociais (fanpages e Twitter).

Recorrendo às evidências empíricas, o programa de Aécio Neves (PSDB), que foi ao ar em cadeia nacional de televisão no HGPE, no dia 02 de outubro, a três dias da eleição presidencial, é elucidativo das questões teóricas apontadas sobre a cultura da mineiridade e o tom personalista. O programa, com duração de 4 minutos e 35 segundos, é centrado na figura de Aécio Neves, num tom personalista - agregando atributos pessoais e políticos, conforme explica Albuquerque (1999).

A propaganda do candidato tem um tom personalista e explora uma dimensão espetacular ao procurar comover o público sobre a trajetória do candidato (GOMES, 2004). O programa começa com imagens da cidade histórica de São João del-Rei, em Minas Gerais, onde Aécio Neves e, principalmente, a memória da trajetória política de Tancredo Neves, seu avô é muito forte. Imagens das igrejas barrocas, das ruas são mostradas até que aparece a imagem de Aécio, num enquadramento intimista que remete à pacatez, à tradição e ao convívio familiar. É quando o candidato justifica a sua candidatura e fala de suas qualidades políticas resgatando a família e a herança política herdada de seu avô. Sentado de forma bem tranquila na sala, junto à família, a esposa Letícia com os filhos recém-nascidos, a filha Gabriela e a irmã Andréa Neves. Diante da família e como pano de fundo imagens da cidade de São João del-Rei o discurso explora o emotivo, vinculado o candidato às raízes mineiras. A fala é num tom intimista.

No momento em que se aproximam as eleições, eu queria agradecer muito, mas muito mesmo a você, que conheceu as nossas propostas, que acompanhou os nossos debates e que com certeza compreendeu as razões que me levaram a disputar a Presidência da República. E eu peço licença para agradecer também a minha família, à Letícia, minha esposa, à minha mãe, a minha filha Gabriela, as minhas irmãs, pela compreensão que tiveram durante todo este tempo. Andei pelo Brasil sempre me lembrando de onde as coisas começaram para mim. Começaram aqui, na minha São João del-Rei, ao lado do meu avô Tancredo, caminhando por estas ruas e aprendendo muito cedo que decência e política podem e devem caminhar sempre juntas. É daqui que quero reiterar o meu compromisso em continuar a minha caminhada como sempre fiz, acreditando que a generosidade, aliada à ética, à honestidade, pode me levar a construir um Brasil muito melhor do que este que nós temos, um Brasil que volte a nos trazer esperança. Eu estou pronto e conto com o seu apoio (AÉCIO NEVES, 02 de outubro de 2014, em programa na TV no HGPE). 
Fica evidente na fala do candidato, primeiramente, o tom personalista - Aécio é a liderança, sem fazer qualquer menção ao seu partido PSDB e de sua coligação. De uma forma sutil, ele aparece como o chefe da família - sentado e frente a ele as mulheres que estão sob sua proteção, mas dando apoio - esposa, mãe, irmãs. Pode-se, inclusive, identificar que, ao fazer referência ao avô, simbolicamente, quis construir a ideia de que hoje ocupa o espaço tanto na família como na política antes ocupado por Tancredo Neves. Em segundo lugar, procura mostrar a sua serenidade, o tom pacato das cidades e dos mineiros (ARRUDA, 1990).

O seu depoimento tem como pano de fundo as ruas da cidade histórica, denominada por ele "a minha São João del-Rei", que remete a vivências da sua infância, ou seja, a questão da memória, outra característica da cultura mineiridade. Ruas que são mostradas e que mantêm o tom tradicional da cidade, ruas nas quais ele afirma que percorria e onde aprendeu lições de vida e da política. Conciliando atributos pessoais e políticos, das funções familiares exemplares (o pai, o irmão presente) é que ele aciona a sua missão política - a de transformar o Brasil, com ética, honestidade, decência - qualidades que o candidato alega ter aprendido nas ruas de São João del-Rei e na vivência com o seu avô Tancredo Neves. Há uma valorização mítica do passado, característica forte da cultura da mineiridade.

Na última semana que antecedeu o primeiro turno da eleição, na fanpage do candidato Aécio Neves, fica evidente o tom personalista e a ênfase em traços da cultura da mineiridade, como a família, a religiosidade e a tradição. No dia 03 de outubro, foi postada a seguinte frase do candidato. "Minha avó, dona Risoleta, casada com o presidente Tancredo, dizia sempre que a gratidão é a memória do coração. Esse é o sentimento que tenho por cada brasileiro que me recebeu nesta campanha". A frase de tom emotivo é uma forma de agradecer os eleitores e ao mesmo tempo gerar comoção a partir do resgate da família ao fazer referência a sua avó e ao avô Tancredo Neves.

A religiosidade foi marcante nas postagens antes do primeiro turno. No dia 04 de outubro, na fanpage do tucano, ele fez referência ao Dia de São Francisco de Assim, além de postar a oração do santo. No dia 05 de outubro, dia da eleição, novamente, a fanpage traz outra postagem em que Aécio faz menção a sua esposa e a São Francisco de Assis. "Minha esposa, Letícia, postou hoje no Instagram a Oração de São Francisco e escreveu algumas palavras que me comoveram muito. Gostaria de compartilhar com vocês". Abaixo da frase, foi postada a oração e em seguida o texto em tom bem intimista que a esposa fala de seu amor a Aécio Neves e de seu apoio incondicional a ele durante a campanha.

Ainda no dia 05 de outubro, foi postada a reportagem exibida na Globo News, no Jornal das Dez, que descreve a trajetória e o perfil de Aécio Neves. Na reportagem, intitulada "Aécio convive com a política desde que nasceu", a ênfase é na vivência do tucano na infância e na adolescência em São João del-Rei, em Minas Gerais, onde nasceu. Por meio de depoimentos de familiares, amigos e moradores da cidade, é contada a trajetória de Aécio, ressaltando que São João del-Rei é uma cidade barroca, festiva, que mescla o sagrado e o profano. A matéria frisa ainda que Aécio entrou na vida política como secretário particular do seu avô Tancredo Neves na campanha pelas Diretas Já em 1984.

Fica evidente, nas postagens da fanpage na semana antes do primeiro turno, o tom emotivo e a busca de vincular a imagem de Aécio Neves à cultura da mineiridade, reforçando o seu forte vínculo com São João del-Rei, a sua vivência familiar ligada ao avô Tancredo Neves e a religiosidade como um valor a ser defendido como uma qualidade para quem pretende assumir a presidência da 
República. O caráter personalista mostra a preocupação em fortalecer os atributos pessoais e políticos de Aécio Neves e sequer citar a questão partidária. A principal questão política é trabalhada simbolicamente ao colocar Aécio Neves como o herdeiro político de seu avô Tancredo Neves, um político capaz de mudar o Brasil.

No segundo turno, quando a disputa ficou ainda mais acirrada, Aécio passou a ter o mesmo tempo no HGPE - 20 minutos (distribuído - tarde e noite). Procurou vincular em vários programas ao de seu avô Tancredo, colocando-se como o seu herdeiro político. No programa que foi ao ar, no último dia de campanha, 24 de outubro, a dois dias do pleito, ele se despede e faz referências ao avô.

Minhas amigas, meus amigos, hoje se encerra a propaganda eleitoral e eu quero agradecer e agradecer muito, a sua companhia e a toda a sua família até aqui. Eu iniciei esta campanha dizendo que todos eram muito bem-vindos, bem-vindos a um novo jeito de governar, bem-vindos a um tempo deunião, de mais decência, de mais eficiência, de verdade. Bem-vindos porque assim nós somos, acolhedores, solidários, generosos. Isso é o que nós brasileiros temos de melhor, de mais profundo,o nosso caráter. Algo que não se pode abandonar nunca, nem mesmo numa disputa eleitoral. Viajando de norte a sul, desse maravilhoso Brasil, eu pude sentir o afeto, o carinho e o apoio dos brasileiros, de todas as regiões. Eu senti na pele o entusiasmo de pessoas, e muito mais do que isso um desejo de libertação dos brasileiros. O anseio por um novo caminho. Um caminho que nos permita superar os grandes desafios que teremos pela frente. Por toda parte, vi uma onda de esperança, uma onda de entusiasmo, que tomou conta dos corações dos brasileiros, uma onda pela mudança. Se o passado nos deu lições de união, de coragem, de luta por aquilo que é certo, o nosso presente tem sido uma coleção de decepções. Valores importantíssimos na vida de todos nós, como justiça, verdade, honestidade, respeito, estão se perdendo. Recuperar estes valores fundamentais também é parte da mudança que queremos fazer. A mudança que vai trazer de volta ao Brasil o bom governo. O governo que funcione e que faça o Brasil funcionar. Um governo que melhore de fato a sua vida, que faça o Brasil voltar a crescer, que compartilhe os resultados da prosperidade com todos os brasileiros. (...) Há 30 anos, em me lembro muito bem disso, os brasileiros se uniram em torno o meu avô, Tancredo Neves, para vencer a ditadura e gritaram por todos o país 'Muda Brasil'. Hoje, eu repito a mesma frase - 'Muda Brasil'. A história, você sabe, é feita por pessoas, é feita por todos nós. E hoje, está muito claro, nós estamos prontos para iniciar um novo e belo momento da nossa história, porque a mudança já começou (....) (AÉCIO NEVES, 24 de outubro de 2014, em programa na TV no HGPE).

Como pode ser analisado, mesmo acionando a cultura da mineiridade e recorrendo à memória do avô Tancredo Neves, o discurso de Aécio tem um tom crítico, de se posicionar contrário ao governo que marca o presente dos brasileiros - no caso de se colocar contra o governo da sua adversária, a então presidente e candidata Dilma. Ele fala de um passado de união e vitórias para mencionar um presente carregado de decepções e promete um futuro de esperanças. Tal fala é típica do discurso oposicionista, de que o mundo atual está ruim e só pode melhorar se houver mudanças. Por isso, Aécio fala tanto de mudanças e frisa bem a frase "Muda Brasil", mas faz isso resgatando o capital político do seu avô Tancredo Neves.

Na fanpage, que chegou a 3 milhões de curtidas no segundo turno, Aécio procurou trabalhar valores relacionados à cultura da mineiridade, como várias postagens mostrando a sua participação em eventos religiosos, a importância da família, com fotos do candidato quando ainda era criança, fotos com a sua mulher e os filhos recém-nascidos, fotos de sua cidade natal em Minas, São João del-Rei. A religiosidade e a preocupação em se mostrar como o chefe de uma família 
tradicional mineira foram pontos marcantes para conseguir os votos dos eleitores mais conservadores. Funcionou, também, como uma estratégia de marketing para combater os ataques que surgiram nas redes sociais de que o candidato teria uma vida pessoal conturbada. Mostrar Aécio em São João del-Rei ao lado da família era fundamental para trabalhar os atributos pessoais na sua imagem de um homem ligado a um perfil tradicional. $O$ candidato encerrou a campanha eleitoral com uma visita ao túmulo do avô Tancredo Neves.

\section{A identidade híbrida no HGPE e no ciberspaço: a ênfase na propaganda negativa}

Se a propaganda política de Aécio Neves construiu a sua imagem a partir de características da cultura da mineira, por outro lado, o tom agressivo e a campanha negativa de ataques à Dilma Rousseff revelam uma identidade híbrida. Mesmo que os traços do mineiro, em sua tradição, sejam o de contestador em alguns momentos históricos, como a Inconfidência Mineira, o posicionamento do candidato destoava da imagem pacata e conciliadora do político mineiro. $\mathrm{Na}$ polarização com o governo petista, o candidato Aécio Neves tentou desconstruir a imagem do país, mostrando que o que estava sendo exibido nos programas da petista não refletia uma realidade de problemas vividos pelo brasileiro. Trata-se do clássico discurso da oposição. Aécio afirmou que o Brasil é o país do caos. Para o tucano, as propostas feitas pelo governo petista não foram cumpridas; segundo ele, a única saída seria retirada do PT da Presidência.

O Brasil vive um momento único. Nós nunca passamos por isso. Por décadas seguidas, o Brasil veio avançando. E o Brasil de hoje, sem dúvida alguma, é um país muito melhor do que era algumas décadas atrás. Mas este país é uma construção de muitas pessoas, de vários governos e em especial do esforço de cada brasileiro. Mas infelizmente essa realidade vem mudando e a verdade é que hoje o Brasil está pior do que estava há quatro anos. O fato é que algumas das principais conquistas que nos trouxeram até aqui, hoje estão em risco. Problemas que já tinham sido superados estão agora voltando. A inflação já está aí de novo batendo na sua porta, entrando na sua casa. Na economia, o Brasil parou de crescer. (...). A grande verdade é que as pessoas perderam a confiança na capacidade deste governo de fazer o Brasil avançar. E o Brasil é um país de trabalhadores, de pessoas que lutam para seguir em frente. Mas hoje os brasileiros estão sozinhos, tendo que se virar para resolver os seus problemas. Hoje, o que depende dos brasileiros vem dando certo, mas aquilo que depende do governo vem dando errado. Se os velhos caminhos não levam mais a lugar algum, está na hora de fazermos diferente. É hora de nos unirmos em torno de um ousado projeto de país e não apenas em torno de um projeto de poder (AÉCIO NEVES, programa do HGPE exibido no dia 19 de agosto de 2014).

As propagandas do candidato Aécio Neves no HGPE evidenciam uma postura mais agressiva, enfatizando uma campanha negativa de desconstrução do governo da presidente Dilma Rousseff, o que mostra a ambiguidade entre o estilo mineiro de político conciliador e o tom combativo adotado na campanha. No primeiro dia propaganda eleitoral, dia 19 de agosto de 2014, Aécio apresentou seu slogan "Muda Brasil", que é a de promover mudanças no Brasil e assumiu o compromisso de fazer um Brasil diferente e melhor, com um novo jeito de governar. O candidato mostrou uma visão caótica do país, com "problemas que já tinham sido superados estão agora voltando. A inflação já está ai de novo batendo na sua porta, entrando na sua casa. [...] e o mais grave, os empregos começam a desaparecer" (AÉCIO NEVES, programa no HGPE, 19 de agosto de 2014).

Novamente, no dia 11 de setembro, o tom foi de ataques ao PT. Dessa vez, a temática foi corrupção destacando as denúncias de desvios de recursos na Petrobras. O candidato propôs em seu governo tirar a Petrobrás da política. "Eu 
quero tirar a Petrobras da política. Colocar ali uma diretoria que seja respeitada pelos brasileiros e que permita à nossa maior empresa voltar a ajudar o Brasil a crescer" (AÉCIO NEVES, programa do HGPE, dia 11 de setembro de 2014).

No dia 30 de setembro, em seu programa, Aécio voltou a fazer ataques à adversária e ao PT. “(...) além dos serviços de péssima qualidade, da ineficiência em praticamente todas as áreas do governo e das denúncias de corrupção que não terminam nunca, o PT está deseducando o Brasil. Essa forma de fazer política está destruindo nossos valores, os exemplos que nós aprendemos em nossa casa com nossos pais, nossos avós, a não mentir, a não roubar, a ter decência, a ter respeito" (AÉCIO NEVES, programa do HGPE, 30 de setembro de 2014).

No programa exibido no dia 02 de outubro de 2014, no HGPE, são exibidas imagens e falas da participação de Aécio Neves no debate realizado pela TV Record, no dia 28 de setembro de 2014 , num confronto direto com a presidente Dilma Rousseff. Aécio mostra-se agressivo.

Corrupção na Petrobras - Eu vou tirá-la das mãos deste grupo político que tomou conta da empresa e está fazendo aquilo que nenhum brasileiro poderia imaginar, negócios há 12 anos, senhora presidenta, senhora candidata. E a senhora era presidente do Conselho Administrativo desta empresa. É vergonhoso. Eu expresso aqui a indignação de milhões de brasileiros, as denúncias não cessam. Apenas a denúncia, eu vou ficar apenas nela, do diretor nomeado pelo seu governo, pelo governo do PT e mantido no seu governo, apenas aquilo que ele assume que foi desviado da Petrobras permitiria que 450 mil crianças, seu filho, por exemplo, estivessem numa creche. Possibilitaria que 50 mil casas do Minha Casa, Minha vida estivessem sendo construídas. É aí que está o dolo. É isso que a corrupção impacta na vida das pessoas (AËCIO NEVES, 02 de outubro de 2014, em programa na TV no HGPE).

O segundo turno foi muito mais acirrado e foi, sem dúvida, a disputa presidencial com mais ataques e propaganda negativa desde a eleição de Collor em 1989. Tanto a candidata Dilma Rousseff como Aécio Neves trocaram acusações, principalmente nos quatro debates ocorridos em cadeias de televisão e transmitidas na web ao mesmo tempo - Rede Record, SBT, Bandeirantes e Globo. Vieram à tona críticas de cunho político como questões da vida privada. O mesmo tom ofensivo apareceu na propaganda eleitoral no HGPE e nas fanpagens, porém com um tom mais cuidadoso, tendo em vista que a propaganda negativa excessiva pode gerar descontentamento no eleitor. Aécio fez críticas ao envolvimento do PT nos casos de corrupção, principalmente da Petrobras, bem como em relação à crise econômica que o país já enfrentava em 2014. O candidato do PSDB procurou também se defender dos ataques da propaganda petista, como às referentes aos programas sociais. Nos programas, o PT argumentava que Aécio poderia ser um risco à manutenção das políticas sociais, como o programa "Bolsa Família", que é um dos programas mais bem sucedidos das gestões petistas.

No dia 17 de outubro de 2014, em sua fanpage, Aécio postou uma resposta à crítica do PT: "Aos petistas, o que interessa é a administração da pobreza. A nós, interessa a superação definitiva da pobreza". Dia 17 é o Dia Internacional para Erradicação da Pobreza. E, enquanto o PT procura construir o argumento de que, como situação, garantiria a manutenção do programa e, por outro lado, Aécio, como oposição, era um risco à continuidade do "Bolsa Família", o PSDB tentou desqualificar o discurso, procurando mostrar para o eleitor de que o senador se comprometia a dar continuidade às ações e políticas sociais das gestões petistas, fazendo a ressalva de que iria aprimorar tais iniciativas. 


\section{Considerações Finais}

A partir da revisão da literatura e da análise das propagandas de Aécio Neves (PSDB), pode-se chegar a algumas reflexões importantes. Em primeiro lugar, como esclarecem Bourdieu (1998) e Rodrigues (1990), vivenciamos, na modernidade, uma nova configuração dos campos sociais, em que o campo midiático assume um espaço de centralidade. Há um grande investimento dos atores políticos e uma necessidade de adaptação dos seus discursos à lógica espetacular imposta pela mídia (GOMES, 2004). Isso aponta para uma nova forma de representação política - a "democracia de público" (MANIN, 1995), em que há uma ênfase nas lideranças personalistas. Evidenciou-se, na disputa eleitoral de 2014, o uso exacerbado da mídia a partir de uma narrativa transmidiática (JENKINS, 2009), com discursos tanto na mídia convencional, como na televisão no Horário Gratuito, como na internet e nas redes sociais, a partir das fanpages dos candidatos.

Quanto às identidades construídas na contemporaneidade, fica cada vez mais evidente a construção de identidades híbridas. Aécio Neves procurou agregar a sua imagem os valores da cultura da mineiridade, que remetem a uma posição mais conservadora como o tom conciliador, a religiosidade, a família. Resgatou a imagem de políticos mineiros que se tornaram heróis na história política brasileira, como o seu avô Tancredo Neves. Procurou mostrar para o eleitor que é o herdeiro político da tradição mineira. Escolheu a sua terra natal e de seu avô Tancredo - a cidade barroca de São João del-Rei - para o último programa eleitoral do primeiro turno e para o fechamento da campanha no segundo turno. Num tom emotivo, Aécio aparece ao lado da família mostrando imagens da cidade, onde aprendeu a fazer a "boa política". Mas os programas eleitorais do tucano foram predominantemente de campanha negativa, de ataques à candidata Dilma e ao PT, revelando um tom agressivo e discrepante da imagem do político mineiro conciliador.

\section{Referências}

AGGIO, C. O.. Internet, Eleições e Participação: Questões-chave acerca da participação e do ativismo nos estudos em campanhas Online. In: GOMES, W.; MAIA, R.; MARQUES, F. J. (Orgs). Internet e Participação Política no Brasil. Porto Alegre: Editora Sulina, 2011, p. 175-196.

ALBUQUERQUE, A. 'Aqui você vê a verdade na tevê'. A propaganda política na televisão. Dissertação (Mestrado em Comunicação, Imagem e Informação - MCII) - Universidade Federal Fluminense, Niterói, 1999.

ÂNGELO, M. H. Vozes das Montanhas: a representação do político mineiro em textos de Aécio Neves. Dissertação (Mestrado em Letras da Universidade Federal de São João del-Rei), 2005.

ARRUDA, M. A. N. Mitologia da Mineiridade. São Paulo: Brasiliense, 1990.

BRASIL. Presidência da República. Secretaria de Comunicação Social. Pesquisa Brasileira de Mídia 2015: hábitos de consumo de mídia pela população brasileira. - Brasília: Secom, 2015.

BOURDIEU, P. O poder simbólico. Rio de Janeiro: Bertrand Brasil, 1998.

CASTELLS, M. O poder da identidade. São Paulo: Paz e Terra, 1999.

FOUCAULT, M. Microfísica do poder. Rio de Janeiro: Edições Graal, 2003. 
GOFFMAN, E. A representação do eu na vida cotidiana. Petrópolis: Vozes, 1999.

GOMES, W. Transformações da política na era da comunicação. São Paulo: Paulus, 2004.

HALL, S. A identidade cultural na pós-modernidade. Rio de Janeiro: DP\&A, 2004. JENKINS, H. Cultura da Convergência. São Paulo: Aleph, 2009.

MANIN, B. As metamorfoses do governo representativo. In. Revista Brasileira de Ciências Sociais (RBCS). № 10, out. 1995.

RECUERO, R. Redes Sociais na Internet. Porto Alegre: Editora Sulina, 2009. 